\title{
Benign Parathyroid Gland Neoplasm
}

National Cancer Institute

\section{Source}

National Cancer Institute. Benign Parathyroid Gland Neoplasm. NCI Thesaurus. Code C3630

A benign neoplasm arising from the parathyroid glands. 